Original Research

\title{
Clinical Profile and Nursing Diagnosis of the Newborn in a Special Care Nursery (SCN) Unit
}

\section{Defi Efendi ${ }^{1}$, Yeni Rustina ${ }^{2}$ and Dian Sari ${ }^{3}$}

${ }^{1}$ Department of Pediatric Nursing, Faculty of Nursing Universitas Indonesia Neonatal Intensive Care Unit (NICU), Universitas Indonesia Hospital

2 Department of Pediatric Nursing, Faculty of Nursing Universitas Indonesia Head of Nursing Committee, Universitas Indonesia Hospital

${ }^{3}$ Prima Nusantara Bukittinggi Health Institute, West Sumatra Indonesia

\begin{abstract}
Introduction: A good comprehension of the clinical profile and nursing diagnosis of newborn in Special Care Nursery (SCN) unit guides decisionmaking by nurses. In addition, it can become an initial basis for making plans for improving quality of care, management and nursing research. The purpose of this study was to identify clinical profile and nursing diagnosis of newborns in an SCN unit.
\end{abstract}

Methods: It is a quantitative, cross-sectional, descriptive study in SCN (Level II and III) with a sample of 77 medical records of newborns less than 31 days old in a national referral hospital. Descriptive analysis was used to identify demographic characteristic, the medical diagnosis and nursing diagnosis of newborns at birth and hospitalization.

Results: Newborns treated in SCN unit are dominated by preterm with low birth weight (74\%). Respiratory system disorders (55.8\%) and infections (35.1\%) dominate newborn problems both at birth or coming. Most nursing diagnoses when the baby is born or coming are the risk of infection (90.9\%) and ineffective breathing patterns (76.6\%). As for the treatment, most diagnoses show the risk of infection and hypovolemia.

Conclusion: A good clinical profile and nursing diagnosis of newborns can guide nurses to decision-making. Continuous update on nursing diagnosis determination, improvement of nurses' knowledge about the signs of deterioration, and future research that prioritizes issues in neonates are required to optimize nurses' role in SCN units.

\section{ARTICLE HISTORY}

Received: October 21, 2020

Accepted: April 29, 2021

\section{KEYWORDS}

newborns; nursing diagnosis; special care nursery

\section{CONTACT}

Defi Efendi

$\triangle$ defiefendi@ui.ac.id

$\equiv$ Department of Pediatric Nursing, Faculty of Nursing Universitas Indonesia

Neonatal Intensive Care Unit (NICU), Universitas Indonesia Hospital

Cite this as: Efendi, D., Rustina. Y., \& Sari, D. (2021). Clinical Profile and Nursing Diagnosis of the Newborn in a Special Care Nursery (SCN) Unit. Jurnal Ners, 16(2). 101-105. doi:http://dx.doi.org/10.20473/in.v16i2.22626

\section{INTRODUCTION}

Neonates have the highest risk of health issues that can potentially lead to death. Globally, almost 2.5 million babies in the world die within their first month of life (neonatal age). Most neonatal death (75\%) happens in the first week of life, and approximately one million neonates die in the first 24 hours of life. Premature birth, perinatal asphyxia, infection, and birth defects are the main causes of neonatal mortality (WHO, 2019). The Indonesia Demographic and Health Survey (IDHS) in 2017 indicated that the neonatal mortality rate was 15 per 1,000 live births. This number showed a decrease compared to 2012, when the neonatal mortality rate was 19 per 1,000 live birth (Ministry of Health Republic of Indonesia, 2018).

The reduction of neonatal mortality requires cooperation among healthcare professionals, families, and the community to provide excellent and continuous health services for mothers during pregnancy and delivery, and for mothers and neonates during the neonatal period (Ministry of Health - Republic of Indonesia, 2010). Among the delivery of health services to neonatal is services to the perinatology unit. One of the important elements in providing quality services in the perinatology unit is nursing. The 2014 constitution of The Republic 
Indonesia mandated that nursing services are an integral part of health services based on nursing knowledge and tips (Constitution of The Republik Indonesia, 2014). Through their knowledge and skills, nurses are expected to be able to make a major contribution in the process of solving various problems in the unit. Article 29 No. 38 of the constitution outlines the authority of nurses to be able to provide comprehensive nursing services including nursing care, executing assignments overflow, as counselors, service managers, and researchers.

In nursing care, nurses are guided through the nursing process, which includes assessment, nursing diagnosis, intervention, implementation and evaluation. One of the important elements in the nursing process is the nursing diagnosis. Nursing diagnoses help nurses see the patient holistically and create nursing plans. A good nursing diagnosis can result in good quality of care and strengthen their professional role (Håkans, 2012). To be able to achieve this, basic data are needed that describe the initial conditions of the newborn along with the nursing diagnosis that is enforced. Nursing studies about it are limited and there is no research that describes the uniqueness of newborns in Indonesia.

Based on this, it is necessary to build baseline data related to neonatal conditions in the form ofclinical profiles and diagnosis of neonates undergoing hospitalization in an SCN unit. This basic data for nursing development can be further utilized such as (1) developing nursing intervention protocols based on priority problems, (2) making nursing care standards based on the most common nursing diagnoses, (3) developing research based on priority nursing problems.

\section{MATERIALS AND METHODS}

A cross-sectional study was used to explore clinical profile and nursing diagnosis neonates in an SCN. We classify SCN as level II and III of care according to the American Association of Pediatrics (AAP) 2012 (Barfield et al., 2012). The number of samples required in the quantitative study was determined using a categorical descriptive formula in accordance with the expected main outcome (Dahlan, 2016) (i.e., the nursing diagnosis). With 5\% alpha, 20\% nursing diagnosis proportion, and 0.09 precision, thisresulted in 76 for the minimum number of samples. Therefore, this study examined 77 medical records (MR), which were selected by using a proportional random sampling technique. Samples comprised complete documents for babies less than 31 days old who were born between January and December, 2016 in a national referral hospital. The medical record includes neonatal demographic data, neonatal symptom signs at birth and hospitalization, medical diagnosis and nursing diagnosis at birth and hospitalization. These data were analyzed descriptively using the Statistical Package for Social Sciences (SPSS). The descriptive analysis of the quantitative variables involved of percentage, mean, standard deviation (SD). Data were collected in a special care nursery unit in a national referralhospital between June and August, 2017.

This research obtained ethical approval from the institutional review board of the Faculty of Medicine Universitas Indonesia: No. 671/UN2.F1/ETIK/2017.

\section{RESULTS}

The results of an analysis of the quantitative data are presented in the following table and graphics. Table 1 is the demographic data of neonates, while graphics 1,2 , and 3 present the signs and symptoms at birth and during treatment, the medical diagnosis and the nursing diagnosis at birth and during treatment, respectively.

The respondents of this study were dominated by premature infants with average 33.57 weeks, birth weight average 2016.97 gr. Forty-nine babies were born by caesarean delivery in the local hospital (not a referral hospital) (65\%). Fifty-four percent were male and $45 \%$ were female.

The newborns' signs and symptoms during hospitalization were dominated by mucosal secretions of the respiratory tract $(n=29 \quad(37.7 \%)$, desaturation $(n=25(32.5 \%))$, and chest wall retraction $(n=24(31.2 \%))$. Hypotonia, grunting, cold acral and pale body were the clinical conditions that were found only in the first few hours of life and were not reported in the following days.

The most common disorders and medical diagnoses at birth were respiratory system disorders $(n=43)$, immunity/infection disorders $(n=27)$, cardiovascular system disorders $(n=14)$, and surgery case. The number of respondents with these disorders increased with the length of stay. Hyperbilirubinemia, indigestion, and central nervous system disorders were new problems that arose after treatment.

Risk of infection was the most frequent diagnosis identified by nurses on the first day of life and during treatment. During hospitalization, fluid volume deficit, ineffective airway clearance, imbalanced nutrition (i.e., less than body requirements), and ineffective breathing patterns were also diagnosed by nurses.

\section{DISCUSSION}

This study aimed to identify clinical profile neonatal (demographic data, neonatal symptom signs at birth and hospitalization, medical diagnosis at birth and hospitalization) and nursing diagnosis newborn at birth and hospitalization in a Special Care Nursery from admission and during hospitalization. An SCN unit specializes in taking care of neonates aged 0-28 days. Neonates have the highest risk of death-up to 60-80\% (Ministry of Health - Republic of Indonesia., 2018; WHO, 2018). Most neonatal patients (74.02\%) who were treated in the SCN unit were premature infants. This is in line with the observation of Chawanpaiboon et al. (2019), who included Indonesia 
in the five countries with the greatest number of preterm births. Premature infants are helpless human beings with diverse health problems (Trembath, Payne, Colaizy, Bell, \& Walsh, 2016) who need complex support, both from specialized equipment and services (Trembath et al., 2016). Under certain conditions, preterm infants in an SCN unit of a hospital must be referred to another hospital. In this study, respiratory disorder was the main problem faced during treatment. This was because most of the respondents were preterm infants. Parkash, Haider, Khoso, and Shaikh, (2015) state that $33 \%$ of treated neonates were admitted with a gestational age of less than 28 weeks, resulting in respiratory disorder being the main reason for babies to receive treatment, except if the baby was born with congenital anomalies or surgical conditions.
Caesarean delivery was also considered a factor contributing to respiratory disorder in neonates (Kotecha, Gallacher, \& Kotecha, 2016). Chest retraction, cyanosis, and grunting were the most frequently found symptoms in newborns, and these also led to the syndrome of respiratory disorder (Parkash et al., 2015). Another problem in this research is oxygen desaturation. Oxygen desaturation in preterm infants happened when oxygen saturation fell below $80 \%$ / or $85 \%$ for $>10$ seconds (Chawanpaiboon et al., 2019; Fairchild. Nagraj, Sullivan, Moorman, \& Lake, 2019; Paliwoda, New, Davies, \& Bogossian, 2018). Martinez et al. (2012) state that desaturation and bradycardia in premature infants is related to cardiorespiratory instability and respiratory control immunity.

Table 1. The Demographic of Neonates $(n=77)$

\begin{tabular}{|c|c|c|c|c|c|c|}
\hline Variable & $\mathbf{N}$ & (\%) & Mean & Min-Max & SD & $\mathrm{CI} \pm 95 \%$ \\
\hline \multicolumn{7}{|l|}{ Sex } \\
\hline Male & 42 & $54 \%$ & & & & \\
\hline Female & 34 & $45 \%$ & & & & \\
\hline Ambiguous genitalia & 1 & $1 \%$ & & & & \\
\hline \multicolumn{7}{|l|}{ History of Resuscitation } \\
\hline Yes & 35 & $45 \%$ & & & & \\
\hline No & 42 & $55 \%$ & & & & \\
\hline \multicolumn{7}{|l|}{ Birthplace } \\
\hline On-site & 65 & $84 \%$ & & & & \\
\hline Off-site / Referral & 12 & $16 \%$ & & & & \\
\hline \multicolumn{7}{|l|}{ Type of Labor } \\
\hline Normal & 28 & $36 \%$ & & & & \\
\hline Sectio Caesarea & 49 & $64 \%$ & & & & \\
\hline \multicolumn{7}{|l|}{ Birth Weight } \\
\hline$>4000 \mathrm{gr}$ & 2 & $3 \%$ & & & & \\
\hline Normal (2500-4000 gr) & 18 & $23 \%$ & & & & \\
\hline Low Birth Weight (1500-2500 gr) & 32 & $42 \%$ & & & & \\
\hline Very Low Birth Weight (1000- 1500 gr) & 20 & $26 \%$ & & & & \\
\hline Extremely Low Birth Weight (<1000 gr) & 5 & $6 \%$ & 2016.97 & $680-4110$ & 844.885 & $1825.21-2208.74$ \\
\hline \multicolumn{7}{|l|}{ Gestational Age } \\
\hline Extremely preterm < 28 week & 8 & $10.3 \%$ & & & & \\
\hline Very preterm $28-<32$ week & 13 & $16.9 \%$ & & & & \\
\hline Moderate to late preterm $32-<37$ week & 36 & $46.7 \%$ & & & & \\
\hline Term 37-41 week & 20 & $26.1 \%$ & 33.57 & $24-41$ & 3.928 & $32.68-34.46$ \\
\hline Post term $\geq 42$ week & 0 & $0 \%$ & & & & \\
\hline
\end{tabular}

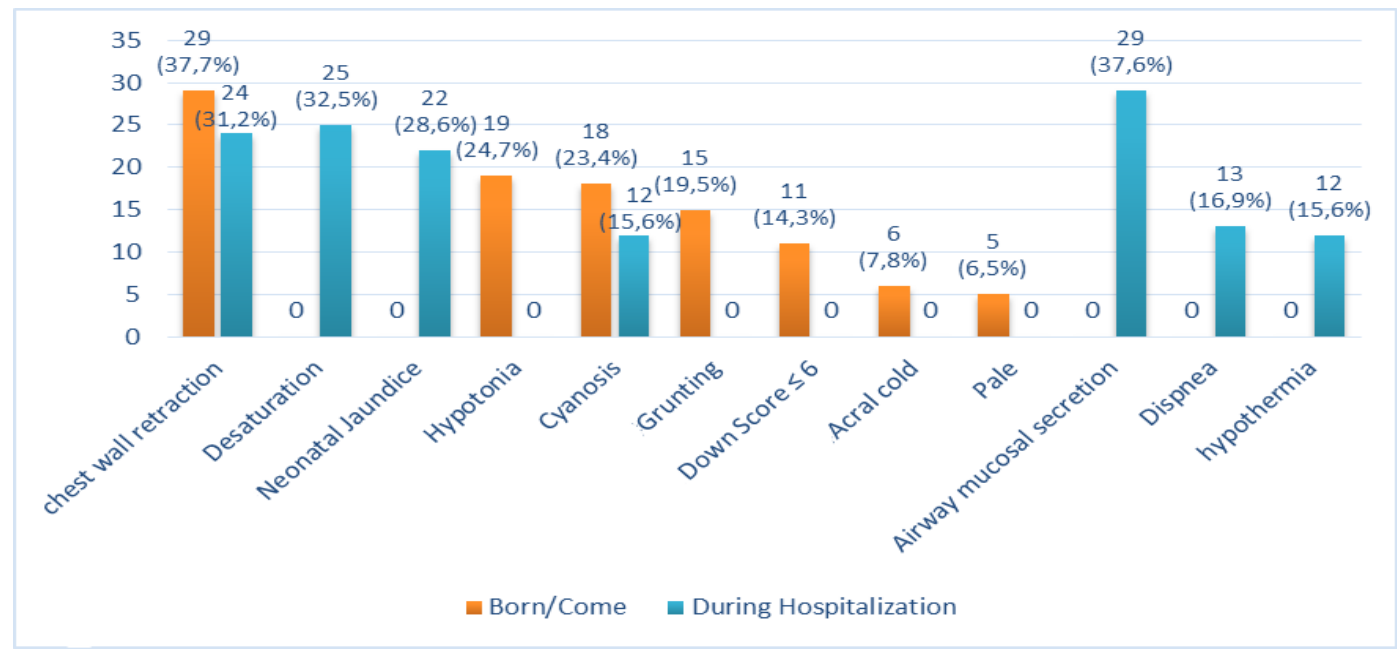

Figure 1. Signs and Symptoms of the Newborn at Birth and During Hospitalization 


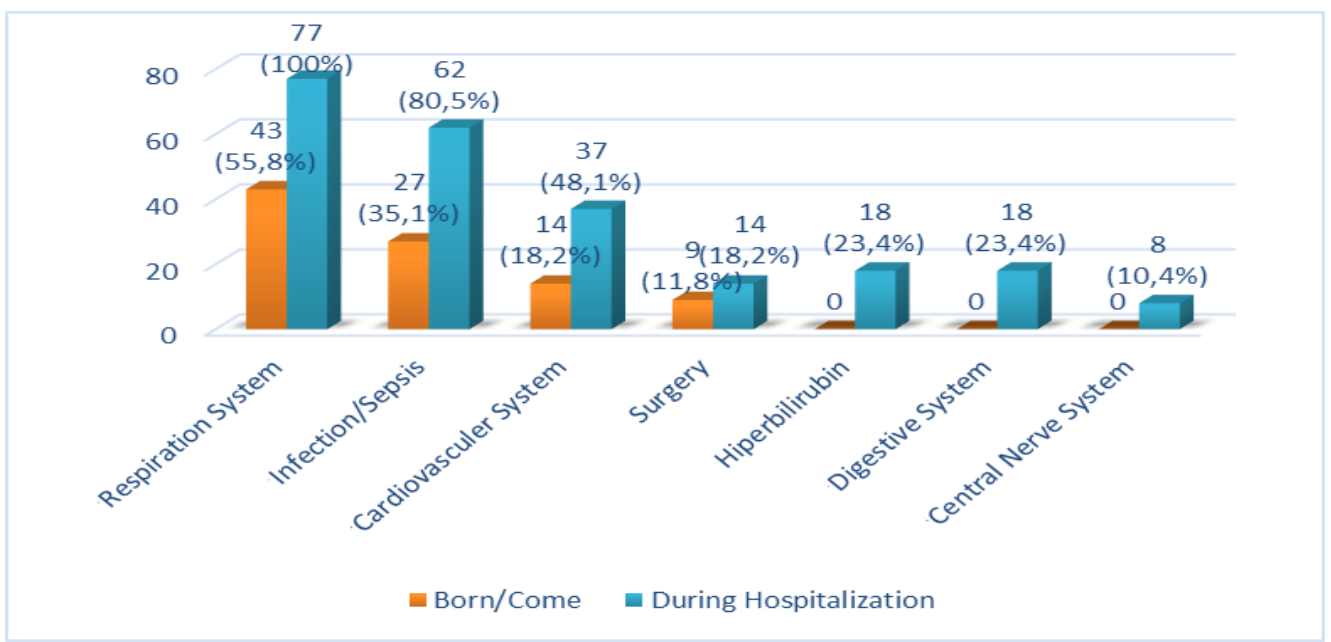

Figure 2. Medical Diagnosis at Birth and During Hospitalization

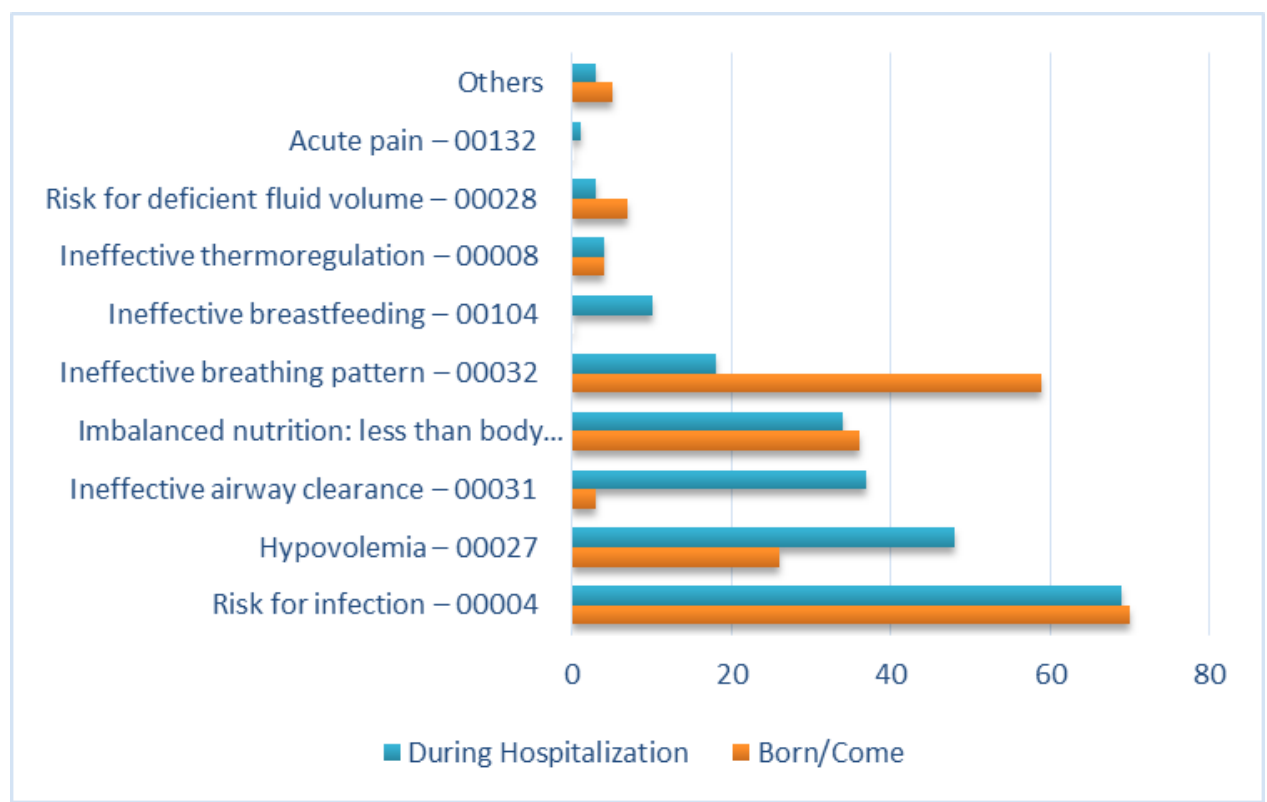

Figure 3. Nursing Diagnosis at Birth and During Hospitalization

In line with symptoms, nursing diagnosis of ineffective breathing patterns is one of the biggest problems with an incidence of more than $75 \%$ when the baby is born or comes to the hospital.

Neonatal sepsis was the most common problem in this study of hospitalized neonates (i.e., 62 respondents (80.5\%)). Globally, infection was the second leading cause of neonatal mortality(Trembath et al., 2016; WHO, 2019) and is an issue especially in developing countries (Adatara et al., 2018). In our study, risk of infection was the most frequently identified nursing diagnosis-69 respondents $(89.61 \%)$ identified risk for infection. Many factors contribute to the increased susceptibility of premature babies to infection. They are innate immunity consisting of barrier, inflammatory response and cells that fight infection having not developed significantly compared to term infants (Collins, Weitkampb, \& Wynn (2018). In line with this, the infection risk nursing diagnosis became the most frequently raised diagnosis both at birth / at and during hospitalization.

The most common nursing diagnosis in this research is deficient fluid volume. Problem in fluid in neonates likes dehydration generally results from inadequate fluid intake, often a result of inadequate breast-feeding (Jobe, 2007). In addition, when coordination is poor between sucking and swallowing, especially in the late preterm infant (GA 34-36 weeks), it increases the risk of dehydration. This condition was related to the immaturity of gastrointestinal function and NEC/necrotizing enterocolitis (Nsibande et al., 2013).

\section{CONCLUSION}

The new-borns treated in the SCN unit were mostly late preterm babies with low birth weight (15002500 gram). Respiratory distress and infection dominated the nursing diagnoses at birth/admission and during treatment. The most common nursing diagnoses were risk for infection and ineffective 
breathing pattern. Continuous update on nursing diagnosis determination, improvement of nurses' knowledge about the signs of deterioration, and future research that prioritizes issues in neonates are required to optimize nurses' role in SCN units.

\section{REFERENCES}

Adatara, P., Afaya, A., Salia, S. M., Afaya, R. A., Kuug, A. K., Agbinku, E., \& Agyabeng-fandoh, E. (2018). Risk Factors for Neonatal Sepsis : A Retrospective CaseControl Study among Neonates Who Were Delivered by Caesarean Section at the Trauma and Specialist Hospital , Winneba , Ghana. Biomed Research International, 7. https://doi.org/https://doi.org/10.1155/2018/6 153501

Barfield, W. D., Papile, L. A., Baley, J. E., Benitz, W., Cummings, J., Carlo, W. A., Kumar, P., Polin, R. A., Tan, R. C., Watterberg, K. L., Macones, G., Jefferies, A. L., Mainous, R. O., Raju, T. N. K., Wang, K. S., \& Couto, J. (2012). Levels of neonatal care. Pediatrics, 130(3), 587-597. https://doi.org/10.1542/peds.2012-1999

Chawanpaiboon, S., Vogel, J. P., Moller, A. B., Lumbiganon, P., Petzold, M., Hogan, D., Landoulsi, S., Jampathong, N., Kongwattanakul, K., Laopaiboon, M., Lewis, C., Rattanakanokchai, S., Teng, D. N., Thinkhamrop, J., Watananirun, K., Zhang, J., Zhou, W., \& Gülmezoglu, A. M. (2019). Global, regional, and national estimates of levels of preterm birth in 2014: a systematic review and modelling analysis. The Lancet Global Health, 7(1), e37-e46. https://doi.org/10.1016/S2214109X(18)30451-0

Collins, A.M., Jörn-Hendrik Weitkampb, J-H, \& Wynn, J.L. (2018). Why are preterm newborns at increased risk of infection? Archives of Disease in Childhood - Fetal and Neonatal Edition, 103(=), F391-F394. https://doi.org/10.1136/archdischild-2017313595

Constitution of The Republik Indonesia. (2014). Constitution of The Republik Indonesia about Nursing.

Dahlan, M. S. (2016). Besar Sampel dalam Penelitian Kedokteran dan Kesehatan (5th ed.). Epidimiologi Indonesia.

Fairchild, K. D., Nagraj, V. P., Sullivan, B. A., Moorman, J. R., \& Lake, E. (2019). Oxygen desaturations in the early neonatal period predict development of bronchopulmonary dysplasia. Pediatr Res, 85(7), 987-993. https://doi.org/10.1038/s41390-0180223-5.0xygen

Håkans, V. B. (2012). Nurses' perception of nursing diagnosis. NI 2012 : 11th International Congress on Nursing Informatics, June 23-27, 2012, Montreal, Canada. International Congress in Nursing
Informatics (11th: 2012: Montreal, Quebec), 2012(2006), 54.

Jobe, A. H. (2007). Neonatal dehydration and neurodevelopment. The Journal of Pediatrics, 151(2), 32887.

Kotecha, S. J., Gallacher, D. J., \& Kotecha, S. (2016). The respiratory consequences of early-term birth and delivery by caesarean sections. Paediatric Respiratory Reviews, 19, 49-55. https://doi.org/10.1016/j.prrv.2015.12.002

Martinez, A. M., Thi, D., Khu, K., Boo, N. Y., Neou, L., Saysanasongkham, B., \& Partridge, J. C. (2012). Barriers to neonatal care in developing countries : Parents ' and providers ' perceptions. Journal of Pediatrics and Child Health, 48, 852-858. https://doi.org/10.1111/j.14401754.2012.02544.x

Ministry of Health - Republic of Indonesia. (2010). Neonate Service Pocket Book (Buku Saku Pelayanan Neonatus). Ministry of Health - Republic of Indonesia.

Ministry of Health - Republic of Indonesia. (2018). Indonesian Health Profile for 2017 (Profil Kesehatan Indonesia Tahun 2017). Ministry of Health - Republic of Indonesia. www.kemenkes.go.id

Nsibande, D., Doherty, T., Ijumba, P., Tomlinson, M., Jackson, D., Sanders, D., \& Lawn, J. (2013). Assessment of the uptake of neonatal and young infant referrals by community health workers to public health facilities in an urban informal settlement, KwaZulu-Natal, South Africa. BMC Health Services Research, 13(1), 1. https://doi.org/10.1186/1472-6963-13-47

Paliwoda, M., New, K., Davies, M., \& Bogossian, F. (2018). Physiological vital sign ranges in newborns from 34 weeks gestation: A systematic review. International Journal of Nursing Studies, 77(October 2017), 81-90. https://doi.org/10.1016/j.ijnurstu.2017.10.004

Parkash, A., Haider, N., Khoso, Z. A., \& Shaikh, A. S. (2015). Frequency, causes and outcome of neonates with respiratory distress admitted to Neonatal Intensive Care Unit, National Institute of Child Health , Karachi. Journal of Pakistan Medical Association, 65(7), 771-775.

Trembath, A. N., Payne, A. H., Colaizy, T. T., Bell, E. F., \& Walsh, M. C. (2016). The problems of moderate preterm infants. Seminars in Perinatology, 40(6), 370-373.

https://doi.org/10.1053/j.semperi.2016.05.008

WHO. (2018). Care of the preterm and low-birthweight newborn. https://www.who.int/maternal_child_adolescent /newborns/prematurity/en/

WHO. (2019). Newborns: Reducing mortality. http://www.who.int/mediacentre/factsheets/fs3 $33 / \mathrm{en} /$ 